\title{
Direct Investment in Conservation Measures by a Public Utility
}

\author{
Anthony M. Marino* and Joseph Sicilian**
}

During the period $1978-1980,{ }^{1}$ public policy toward U.S.-regulated utilities mandated residential conservation programs. Public utilities encouraged residential customers to invest in home conservation measures to help meet the national goal of energy security. The actual programs growing out of this legislation can be grouped as information programs (such as the energy audit program), financial incentives or subsidy programs, and direct investment programs. Our focus is on the third type wherein the public utility itself does home-retrofit conservation work (weather stripping, caulking, storm windows and doors, and attic and wall insulation), and the residential customer pays no direct charges. (In Marino and Sicilian (1986) we provide an economic analysis of information and financial incentives programs.) Our principal goals are: (a) to give an economic explanation of why a regulated utility would want to provide conservation measures that reduce the demand for its primary product and (b) to examine whether existing regulatory structure and utility programs are likely to lead to economic efficiency in conservation investment. We also provide an idealized regulatory structure and conservation program that does lead to economic efficiency.

The following section presents a simple dynamic model of a regulated utility with a direct investment conservation program. Conservation and new generating-capacity investments are treated asymmetrically in that the former investment creates immediate energy saving, while the latter investment can

The Energy Journal, Vol. 8, No. 2

Copyright (C) 1987 by the International Association of Energy Economists. All rights reserved.

The first author's research was supported by research grants from the University of Southern California. The second author's research was supported by a research grant from the University of Kansas. The authors thank an anonymous referee of this journal for helpful comments.

*Department of Finance and Business Economics, Graduate School of Business Administration, University of Southern California, Los Angeles, Calif. 90089.

**Department of Economics, University of Kansas, Lawrence, Kans. 66045

1. See Energy Security Act (1980) and National Energy Conservation Policy Act (1978). 
create only future increases in capacity. Our regulatory apparatus is patterned after existing conservation programs of Pacific Power and Light and General Public Utilities. Following the general strategy of these programs, our model assumes that the public utility issues no direct charges for conservation measures and is permitted to place conservation investment expenditures in the rate base. After providing an explanation for the incentive for conservation investment, this section concludes that such a program is unlikely to lead to economic efficiency.

The third section provides an idealized direct investment program and regulatory policy that does generate economic efficiency. The key ingredients of this policy are as follows: the public utility is permitted to issue charges for its true final products, which we take as a comfort index; conservation and new generating-capacity investments are given rate-base treatment; and the rate-of-return constraint guarantees and allowed rate of return on the present value of conservation and generating-capacity investments for a period starting at the time these investment decisions are made and ends when returns from these decisions have been reaped. The last section briefly summarizes our analysis.

\section{THE PUBLIC UTILITY DOES NOT CHARGE FOR CONSERVATION MEASURES}

We now consider a public utility producing one primary product, referred to as electricity. Electricity is produced using two inputs: a capital input called generating capacity and an operating input called fuel. Letting $x$ be the quantity of electricity produced during a given time period, $L$ the quantity of fuel used, and $K$ the quantity of generating capacity available, we suppose that the technology is described by a production function

$$
x=F(L, K)
$$

We assume that investment in generating new capacity requires an extended period of time, and thus we consider two periods. In the first one, the firm can alter $L$, but a decision to invest in new generating capacity will not alter $K$ until the second period. Let $I$ be the investment in generating capacity. Then with $K^{t}$ denoting the stock of generating capacity in period $t$, we have $K^{2}=K^{1}+I$. In this model, the firm cannot alter $K^{1}$ but can alter $K^{2}$ by choosing $I$. Then letting $x^{t}$ be electricity output and $L^{t}$ be fuel input in period $t$, we have

$$
x^{1}=F\left(L^{1}, K^{1}\right)
$$


and

$$
x^{2}=F\left(L^{2}, K^{2}\right)=F\left(L^{2}, K^{1}+I\right)
$$

We assume that the public utility is subject to rate-of-return regulation. The regulator does not set prices but rather sets a maximum rate of return the utility is allowed to earn on its investment in capital. The utility can choose any price structure as long as demand is met at the chosen prices and the maximum rate of return is not exceeded. Let $r$ be the market rate of interest and $s$ be the regulator's allowed rate of return on capital (we assume that $s>r$ ).

We now introduce into this traditional set-up a conservation commodity, which we think of as a capital good capable of reducing the demand for electricity. It can be provided quickly, relative to the time required to install generating capacity, and, if provided, it will be available in both periods. Let $C$ be the quantity of conservation capital. Letting $p_{x}^{t}$ be the price of electricity in period $t$, the demand for electricity in each period is represented by the inverse demand function

$$
p_{x}^{t}=p_{x}^{t}\left(x^{t}, C\right), \quad t=1,2
$$

We will assume that $\partial p_{x}^{t} / \partial x^{t}<0$ and $\partial p_{x}^{t} / \partial C<0$. That is, demand for $x$ is decreasing in $x$, and $x$ and $C$ are substitutes in consumption.

As in existing direct investment programs, the public utility does not charge its customers directly for providing the conservation commodity, but it may be motivated by other aspects of the regulatory structure to provide conservation. We will suppose that the regulator does count conservation capital as part of the utility's rate base (the stock of capital upon which the utility is allowed to earn the regulated rate of return). We want to know whether this is sufficient motivation for the utility to provide conservation.

To summarize, the utility has an existing generating capacity $K^{1}$ and will choose $L^{1}, L^{2}, I$, and $C$. Then $x^{1}$ and $x^{2}$ are determined by Equations (1) and (2), and $p_{x}^{1}$ and $p_{x}^{2}$ are determined by Equation (3). Electricity revenue in the first period is determined by the choice of $L^{1}$ and $C$ and is given by

$$
R_{x}^{1}\left(L^{1}, C\right)=p_{x}^{1}\left(F\left(L^{1}, K^{1}\right), C\right) \cdot F\left(L^{1}, K^{1}\right)
$$

Electricity revenue in the second period is determined by the choice of $L^{2}, I$, and $C$ and is given by

$$
R_{\ddot{x}}^{2}\left(L^{2}, I, C\right)=p_{x}^{2}\left(F\left(L^{2}, K^{1}+I\right), C\right) \cdot F\left(L^{2}, K^{1}+I\right) .
$$


If $w$ is the price of fuel, profits in the two periods are given by

$$
\pi^{1}\left(L^{1}, I, C\right)=R_{x}^{1}\left(L^{1}, C\right)-w L^{1}-r\left(K^{1}+I+C\right),
$$

and

$$
\pi^{2}\left(L^{2}, I, C\right)=R_{x}^{2}\left(L^{2}, I, C\right)-w L^{2}-r\left(K^{1}+I+C\right) .
$$

The utility is interested in maximizing the present value of total profits,

$$
\pi\left(L^{1}, L^{2}, I, C\right)=\pi^{1}\left(L^{1}, I, C\right)+\beta \pi^{2}\left(L^{2}, I, C\right),
$$

where $\beta$ is the rate-of-time discount.

The single-period rate-of-return constraints are written as:

$$
s\left(K^{1}+I+C\right)+w L^{1}-R_{x}^{1}\left(L^{1}, C\right) \geqq 0,
$$

and

$$
s\left(K^{1}+I+C\right)+w L^{2}-R_{x}^{2}\left(L^{2}, I, C\right) \geqq 0 .
$$

It has been suggested that inclusion of conservation capital in the utility's rate base may be sufficient to cause the utility to provide such capital. ${ }^{2}$ We find that this is not so in our model. ${ }^{3}$

Proposition 1. A public utility deriving revenue only from the sale of electricity and maximizing profits subject to rate-of-return constraints will not choose to invest in conservation capital. (That is, if $\hat{L}^{1}, \hat{L}^{2}, \hat{I}$, and $\hat{C}$ maximize $\pi\left(L^{1}, L^{2}\right.$, $I, C)$ subject to Equations (9) and (10), then $\hat{C}=0$.)

The intuition behind proposition 1 is that a binding rate-of-return constraint in each period requires that both investment types entering the rate base at time 1 (namely $C$ and $I$ ) must generate equal and positive presentvalue marginal revenue streams for there to be positive conservation and new generating-capacity investments. Because conservation capital serves to decrease electricity revenue in any period $\left(\partial p_{x}^{t} / \partial C<0\right)$ and the sale of electricity is the firm's only source of revenue, conservation capital cannot meet the above restriction for an interior solution.

Because there are regulated public utilities investing in conservation, the model thus far presented is inadequate for understanding observed behavior.

2. See Krasniewski and Murdock (1980).

3. Proofs of all three propositions are available from the authors. 
One possibility is that the real-world public utility is not subjected to a binding rate-of-return constraint at each period. After all, we do not observe public utilities facing rate hearings at each and every point in time corresponding to when choice variable decisions are made. Instead we see rate hearings spaced discretely through time. At a hearing the Averch-Johnson binding rate-of-return constraint is relevant, but between hearings the firm makes resource choices facing prices determined at the last review (as a fixed-price constraint). This description of the regulatory process is presented in Joskow (1974) and in the literature on regulatory lag (see Bailey 1973). In this model, we can formulate the above scenario by assuming that in the first period the utility is forced to meet current demand at a fixed price for electricity and must wait until the second period for a rate review and price amendment. If this is the case, it would be appropriate to replace the first period rate-of-return constraint in Equation (9) with the fixed-price constraint

$$
\bar{p}_{x}^{1}-p_{x}^{1}\left(F\left(L^{1}, K^{1}\right), C\right)=0
$$

and the profit function $\pi$ with

$$
\begin{aligned}
\bar{\pi}\left(L^{1}, L^{2}, I, C\right)= & \bar{p}_{x}^{1} \cdot F\left(L^{1}, K^{1}\right)-w L^{1}-r\left(K^{1}+I+C\right) \\
& +\beta \pi^{2}\left(L^{2}, I, C\right) .
\end{aligned}
$$

We find that under constraint (11), the question of conservation investment centers on the relationship between the fixed price of electricity in period $1, \bar{p}_{x}^{1}$, and the marginal operating cost of electricity production in period 1 . This marginal operating cost is given by

$$
\operatorname{MOC}^{1}\left(L^{1}, K^{1}\right)=\frac{w}{F_{L}\left(L^{1}, K^{1}\right)},
$$

where $F_{i}, i=L, K$, denotes a partial derivative. ${ }^{4}$

Proposition 2. A public utility maximizing the present value of profits subject to a fixed-price constraint in period 1 and a rate-of-return constrain in period 2 may choose to invest in conservation capital for the case where revenue is derived only from the sale of electricity. A necessary condition for such investment to occur is that the marginal operating cost of electricity production in period 1 is greater than the fixed price of electricity in period 1. (That is, if $\left(\hat{L}^{1}\right.$, $\left.\hat{L}^{2}, \hat{I}, \hat{C}\right)$ maximizes $\pi\left(L^{1}, L^{2}, I, C\right)$ subject to Equations (11) and (10), then it may be that $\hat{C}>0$. If $\hat{C}>0$, then $\operatorname{MOC}^{1}\left(\hat{L}^{1}, K^{1}\right)>p_{x}^{1}$.)

4. See note 3 above. 
The economic reasoning underlying proposition 2 is fairly clear. When the operating cost of producing another unit of electricity is greater than the regulated price, profit is raised by decreasing electricity production. Investment in conservation capital is the tool used by the public utility to reduce the demand for and thus the production of electricity. It is interesting that the existence of a spread between operating cost and price is precisely the reason given by public utilities such as Pacific Power and Light and General Public Utilities for implementing their direct conservation investment programs. For Pacific Power and Light, this spread was estimated to be as much as $3.5 \phi$ per kilowatt-hour in the late seventies. ${ }^{5}$

Proposition 2 may tell us why utilities invest in conservation products, but it raises another question. Under the assumptions of proposition 2, the utility will not invest in conservation if the price of electricity is greater than the marginal operating cost of electricity production. However, investment in conservation may be economically desirable (from a social viewpoint) even if the price is greater than this marginal cost. More specifically, conservation investment would be desirable if the cost of saving one unit of electricity through conservation is less than the marginal cost of producing one unit of electricity. Thus even under the assumptions of proposition 2 , the profit motive of the regulated utility does not guarantee that conservation will be provided in all situations where it is desirable. Furthermore, even if it is provided, there is no reason to believe that it will be provided at a level that is optimal in any sense.

\section{THE PUBLIC UTILITY ISSUES COMFORT INDEX CHARGES}

It is apparent from a close examination of propositions 1 and 2 that an important impediment to the optimal implementation of conservation products is the inability of the public utility to charge for those products. We shall consider a somewhat idealized scheme that could be quite successful in bringing about an efficient use of conservation services.

We think of electricity and conservation services as being intermediate inputs into the production of a final product or comfort index we will call, for the purpose of exposition, warmth. Ideally, the utility could be responsible for providing this final good and could charge for warmth rather than for the intermediate inputs to warmth. The utility would then be choosing the mix of electricity and conservation services. We then conjecture that the utility would make an efficient choice of these variables, at least to the extent that the normal regulatory process does not distort decision making away

5. See Marino and Sicilian (1982) and Chicchetti and Shaughnessy (1980) for an analysis of. the Pacific Power and Light Program. 
from an efficient input mix. We will now turn to an examination of this conjecture.

If the public utility were to add an additional unit of generating capacity, with conservation investment fixed, then the same level of warmth could be produced in the second period with a reduction in fuel usage. The quantity of fuel reduction that could be achieved by a one-unit increase in generating capacity is given by

$$
R T S_{K L}\left(L^{2}, K^{2}\right)=\frac{\left(\partial F\left(L^{2}, K^{2}\right) / \partial K\right)}{\left(\partial F\left(L^{2}, K^{2}\right) / \partial L\right)}
$$

(Here RTS stands for rate of technical substitution.) We have assumed that the public utility has one type of capital and that there is scope for substituting capital for an operating input. In reality, utilities use many different capital types and have the ability to substitute aggregate capital for aggregate operating inputs. Thus we think of $L$ and $K$ as aggregate composites.

As an alternative to generating-capacity investment, if the public utility were to add an additional unit of conservation investment, with generating capacity fixed, then the same level of warmth could be produced in each of the two periods with a reduction of fuel usage in each period. Let

$$
W^{t}=W\left(x^{t}, C\right)
$$

denote the warmth production function, and let $W, i=x, C$ denote partial derivatives. Given $W$ fixed, another unit of $C$ achieves a reduction of

$$
R T S_{C L}^{1}\left(L^{1}, K^{1}, C\right)=\frac{W_{C}\left(F\left(L^{1}, K^{\mathrm{i}}\right), C\right)}{W_{x}\left(F\left(L^{1}, K^{1}\right), C\right) \cdot F_{L}\left(L^{1}, K^{2}\right)}
$$

units of fuel in period 1 and a reduction of

$$
R T S_{C L}^{2}\left(L^{2}, K^{2}, C\right)=\frac{W_{C}\left(F\left(L^{2}, K^{2}\right), C\right)}{W_{i}\left(F\left(L^{2}, K^{2}\right), C\right) \cdot F_{L}\left(L^{2}, K^{2}\right)}
$$

units of fuel in period 2. The total present value of fuel saving resulting from a unit of conservation investment is then $w \cdot\left(R T S_{C L}^{1}+\beta R T S_{C L}^{2}\right)$. If there is to be an efficient mix of investment in generating capacity and investment in conservation, then at the margin the present value of fuel saved due to 
conservation investment must equal the present value of fuel saving from investment in generating capacity. That is, we must have

$$
w \cdot\left(R T S_{C L}^{1}+\beta R T S_{C L}^{2}\right)=w \cdot \beta R T S_{K L}
$$

We now consider the behavior of the public utility that produces and charges for warmth and is subject to rate-of-return regulation. We suppose that demand for warmth is represented by the inverse demand functions

$$
p_{W}^{t}=p_{W}^{t}\left(W^{t}\right), \quad t=1,2
$$

With $K^{1}$ fixed, the utility will choose $L^{1}, L^{2}, I$, and $C$. Revenue in period 1 is given by

$$
R_{W}^{1}\left(L^{1}, C\right)=p_{\mathrm{w} /}^{1}\left(W\left(F\left(L^{\mathrm{1}}, K^{\mathrm{i}}\right), C\right)\right) \cdot W\left(F\left(L^{1}, K^{1}\right), C\right),
$$

and revenue in period 2 is given by

$$
R_{W}^{2}\left(L^{1}, I, C\right)=p_{W}^{2}\left(W\left(F\left(L^{2}, K^{1}+I\right), C\right)\right) \cdot W\left(F\left(L^{2}, K^{1}+I, C\right)\right.
$$

Profits in the two periods are given by

$$
\pi_{W}^{1}\left(L^{1}, I, C\right)=R_{W}^{1}\left(L^{1}, C\right)-w L^{1}-r\left(K^{1}+I+C\right),
$$

and

$$
\pi_{W}^{2}\left(L^{2}, I, C\right)=R_{W}^{2}\left(L^{2}, I, C\right)-w L^{2}-r\left(\bar{K}^{-1}+I+C\right)
$$

and the present value of total profits is

$$
\pi_{W}\left(L^{1}, L^{2}, I, C\right)=\pi_{W}^{1}\left(L^{1}, I, C\right)+\beta \pi_{W}^{2}\left(L^{2}, I, C\right) .
$$

The single-period rate-of-return constraints are

$$
s\left(K^{1}+I+C\right)+w L^{1}-R_{W}^{1}\left(L^{1}, C\right) \geqq 0,
$$

and

$$
s\left(K^{1}+I+C\right)+w L^{2}-R_{W}^{2}\left(L^{2}, I, C\right) \geqq 0 .
$$

If the public utility chooses $L^{1}, L^{2}, I$, and $C$ to maximize profits $\pi_{W}$ subject to the rate-of-return constrains in Equations (18) and (19), then the efficiency 
condition (12) will not be satisified. This is because the efficiency condition (12) requires a certain intertemporal efficiency that the separate constraints (18) and (19) of the traditional Averch-Johnson literature do not permit. It may be efficient for the utility to trade off profits in one period for profits in another period, but the single-period rate-of-returns constraints do not allow this. If instead of Equations (18) and (19), the utility faces the intertemporal rate-of-return constraint

$$
s(1+\beta)\left(K^{1}+I+C\right)+w L^{1}+\beta w L^{2}-\left(R_{W}^{1}+\beta R_{W}^{2}\right) \geqq 0,
$$

then the profit-maximizing choice of $L^{1}, L^{2}, I$, and $C$ will satisfy Equation (12). The constraint in Equation (20) says that at the time $C$ and $I$ investment decisions are made (the initial time period) the public utility is guaranteed the allowed rate of return on the present value of these investments, where the present-value time interval allows both investment types to generate returns. We summarize these conclusions in proposition $3 .^{6}$

Proposition 3. Consider the situation where the public utility charges for the comfort index. If the utility chooses $\left(L^{1}, L^{2}, I, C\right)$ to maximize $\pi_{W}\left(L^{1}, L^{2}, l, C\right)$ subject to the single-period rate-of-return constraints in Equations (18) and (19), then the choice will not satisfy the efficiency condition (12). However, if $\left(L^{1}, L^{2}, I, C\right)$ is chosen to maximize $\pi_{W}\left(L^{1}, L^{2}, I, C\right)$ subject to the multiperiod rate-of-return constraint in Equation (20), then this choice will satisfy the efficiency condition (12).

\section{CONCLUDING REMARKS}

Our analysis of direct investment programs provides several general conclusions. First, rate-base treatment of conservation investment expenditures is quite unlikely to guarantee economic efficiency in a program that places no direct or indirect charges on conservation measures. This result holds with continuously binding, as well as lagged, rate-of-return regulation. Second, an important device in providing the utility with the incentive to make an efficient choice of conservation investment is to allow it to charge for its actual final product, which we termed comfort. Finally, in conjunction with such charges, rate-base treatment of conservation and new generatingcapacity investments must guarantee an allowed rate of return on the present value of such investments over a period that permits returns from both types of investments.

6. See note 3 above. 


\section{REFERENCES}

Bailey, E. E. (1973). Economic Theory of the Regulatory Constraint. Lexington, Mass.: D. C. Heath.

Chicchetti, C. J. and R. Shaughnessy (1980). "Is There a Free Lunch in the Pacific Northwest?” Public Utilities Fortnightly 106 (December 18): 11-15.

Energy Security Act, 96th Cong. June 30, 1980. Public Law 96-294.

Joskow, P. L. (1974). "Inflation and Environmental Concern: Structural Change in the Process of Public Utility Price Regulation." Journal of Law and Economics 17 (October): 291-327.

Krasniewski, R. J. and R. J. Murdock (1980). "Residential Conservation Service Programs and Their Cost Recovery." Public Utilities Fortnightly (June 5): 13-18.

Marino, A. M. and J. Sicilian (1982). "Residential Energy Conservation and Public Utilities: Regulatory Strategy,” In M. Crew, ed., Regulatory Reform. Lexington, Mass.: D. C. Heath.

Marino, A. M. and J. Sicilian (1986) "Utility Sponsored Information and Financial Incentive Programs: An Analysis of Economic Efficiency." Resources and Energy 8(September): 245-266.

National Energy Conservation Policy Act, 95th Cong, November 9, 1978. Public Law 95-619. 